Proc. Indian Acad. Sci. (Chem. Sci.), Vol. 96, No. 6, April 1986, pp. 599-605.

(C) Printed in India.

\title{
The chloro-methyl exchange rule and its violations in the packing of organic molecular solids
}

\author{
GAUTAM R DESIRAJU* and JAGARLAPUDI A R P SARMA \\ School of Chemistry, University of Hyderabad, P.O. Central University, Hyderabad, 500 134, \\ India.

\begin{abstract}
Since chlore and methyl groups have nearly the same volume, they may be interchanged in a molecule without altering the crystal structure. Such isostructural behaviour is found when crystal stabilization is mainly through dispersive and repulsive interactions. Violations of this rule are, however, observed when directional forces or weak bonds are involved and the failure of complete chloro-methyl exchange in a substance like hexachlorobenzene, points to the importance of weakly attractive $\mathrm{Cl} \ldots \mathrm{Cl}$ interactions.
\end{abstract}

Keywords. Chloro-methyl exchange; crystal engineering; close-packing; hexachlorobenzene; $\mathrm{Cl} . . \mathrm{Cl}$ interactions.

\section{Introduction}

A continuing challenge in the prediction of the crystal structures of organic molecular solids is the fact that the forces which must be considered are so weak. The stablest crystal structure of most compounds is achieved by optimising a large number of subtle interactions having varying degrees of directionality and electrostatic character. These interactions are not always computationally accurately modelled in all cases. Yet there is a strong impetus to research which attempts extrapolation of organic crystal structures since such information enables a definition of new solid state reactions as well as facilitates the search for compounds with novel physical and electronic properties. Such exercises are indeed essential prerequisites in the systematic design or crystal engineering of organic structures (Thomas 1974; Desiraju 1984; Simonetta 1974).

This problem is essentially solved in those cases where the intermolecular forces are the very weakest, that is for those compounds where the crystal energy is obtained largely as the sum of the dispersive and exchange-repulsion terms (Kitaigorodskii 1973). The familiar Buckingham 6-exp type expression may be used:

$$
\phi_{i j}=-A r_{i j}^{-6}+B e_{i j}^{-C r}
$$

Here the potential energy $\phi_{i j}$ for an atom pair $i, j$ is obtained as a function of $r_{i j}$ and the atom potentials $A, B$ and $C$. While the attractive dispersive $r^{-6}$ term predominates at larger intermolecular distances, the repulsive exponential term is significant at shorter separations. This expression is the cornerstone of the elegant close-packing model of Kitaigorodskii (1973). The main premise here is that since dispersive and repulsive forces are isotropic, solids where only these forces are important tend to crystallize with the greatest economy of space and a maximum co-ordination number of 10 to 14.

\footnotetext{
- To whom all correspondence should be addressed.
} 
Further, since the typical organic molecule is irregularly-shaped, the Kitaigorodskii model predicts (correctly) that space groups such as $P 2_{1} / c, P \overline{1}, P b c a, P 2_{1}$ and $P 2_{1} 2_{1} 2_{1}$ should be especially favoured for molecular crystals. Another well-known feature of this model is that the centre of inversion is normally the only molecular symmetry element which is retained in the crystal with axes and mirror-planes being discarded in many cases.

\section{The chloro-methyl exchange rule}

The consequence of the Kitaigorodskii close-packing model which we shall be concerned with in this article is the so-called 'chloro-methyl exchange rule'. Since the packing of molecules is predicted in such a way that the 'voids' in one are locked into the 'protrusions' of the other, volume and shape considerations hold sway rather than electronic factors. Each non-polar substituent group of a certain volume can be exchanged for another non-polar group of a similar volume without any change in the crystal structure. Since the volumes of the chloro $\left(19 \mathrm{~A}^{3}\right)$ and methyl $\left(24 \mathrm{~A}^{3}\right)$ groups are similar, these two substituents may be interchanged in this manner. Some representative examples are shown in chart 1 . An interesting example of crystal engineering is furnished by the benzyl-benzylidenecyclopentanones 1-C and 1-M shown below (Jones et al 1983; Theocharis et al 1984). Such isostructural compounds form solid solutions in all proportions. Since each of the individual compounds is photoactive in the solid state, the mixed crystals also react to form pseudo-inversion symmetry cyclobutanes (figure 1). Since the chloro-methyl exchange is valid, the different mixed crystals constitute a structural continuum between pure 1-C and $1-M$.

Interestingly, the $\mathrm{Cl}-\mathrm{Me}$ exchange rule may also be used to force molecular conformations into non-native ones. Consider the pair of compounds $2-C$ and $2-M$<smiles>Nc1nc(Cl)cc(Cl)n1</smiles><smiles>CC(C)(Cl)C#N</smiles><smiles>O=C1C(Cl)=C(Cl)C(=O)c2ccccc21</smiles><smiles>O=C1CCC(Cc2ccc(Cl)cc2)C1=Cc1ccccc1</smiles>
1- C<smiles>Cc1cc(Cl)nc(N)n1</smiles><smiles>CC(C)(C#N)C#N</smiles><smiles>CC1=C(C)C(C)=C(Cl)C1=O</smiles><smiles>Cc1ccc(CC2CCC(=Cc3ccccc3)C2=O)cc1</smiles>

Chart 1. 


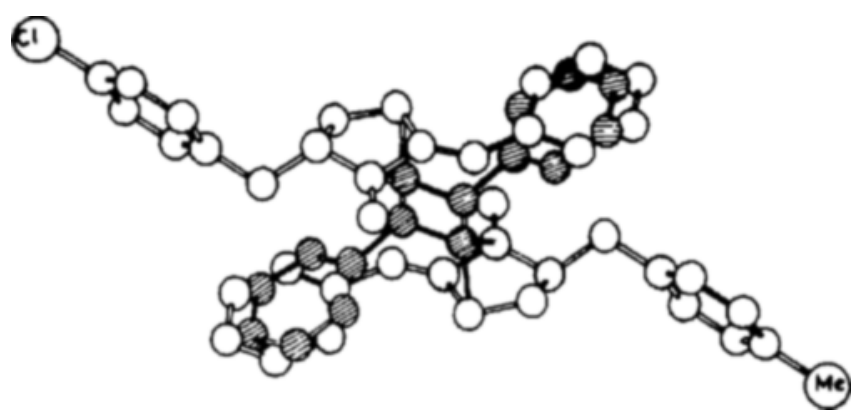

Figure 1. Formation of pseudo-inversion symmetry spirocyclobutane dimer from a crystal (solid solution) of $1-C$ and $1-M$.

(Jones et al 1981). Contrary to expectation, 2-C and 2-M are not isostructural. This means that in certain cases, volume considerations are not adequate and other factors, mainly electronic must be considered. The structural differences in this pair of compounds are marked. Even the molecular conformations are different (figure 2). While $2-M$ adopts a photoactive modification, crystalline $2-C$ is photostable. Yet 2-C and $2-M$ will form mixed crystals $(c a .70 \% 2-M)$, isostructural with $2-M$ primarily as a result of conformational changes imposed upon the minor component 2-C by the dominating major component 2-M (Jones et al 1983; Theocharis et al 1984). In the mixed crystals, the 'photostable' $2-C$ is forced to adopt the molecular conformation, crystal structure and solid state reactivity of the 'photoactive' $2-M$. It may be noted that the methyl derivative 2-M plays a crucial role in steering the structure of 2-C: 2-M mixed crystals towards that of its own structure while simultaneously incorporating increasing
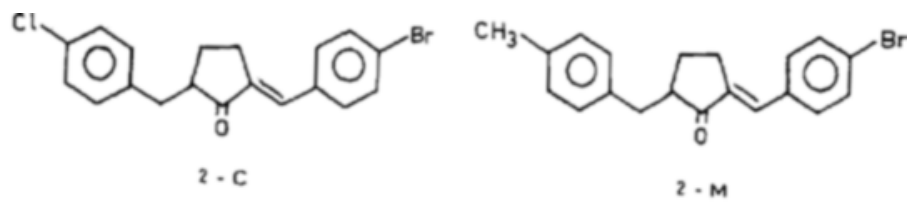

Chart 2.
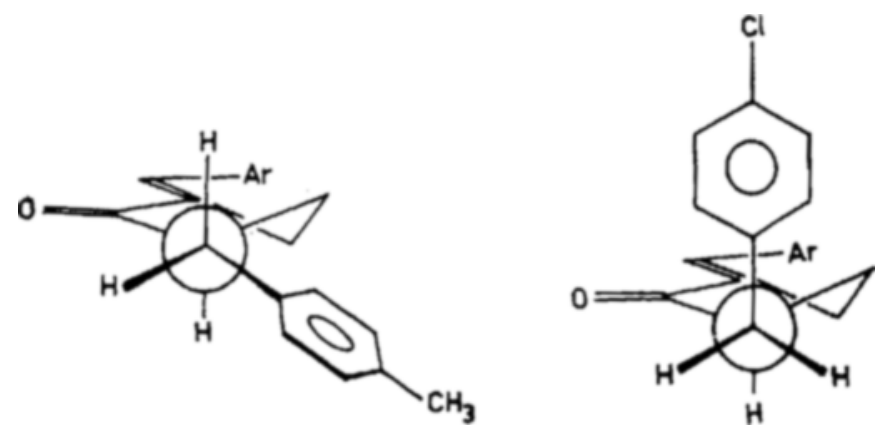

Figure 2. Molecular confirmation of $2-M$ (photoactive) and $2-C$ (photostable) in the solid state. 
amounts of a molecule (2-C) which would prefer to adopt a different structure if taken separately. Cl-Me exchange enables the adoption of an 'unfavourable' conformation and this means that the intermolecular dispersive forces involved in the stabilization of the photoactive mixed crystals evenly match the intramolecular electrostatic forces which stabilize the photostable conformation of 2-C.

\section{Violations of the chloro-methyl exchange rule: $\mathrm{Cl} \ldots \mathrm{Cl}$ interactions}

The geometrical approach of the simple close packing model which results in the Cl-Me exchange rule described above breaks down to a greater or lesser extent when directional and/or electrostatic interactions are involved. When intermolecular forces are not weak, as for example $\mathrm{O}-\mathrm{H} \ldots \mathrm{O}$ hydrogen bonding, considerable deviations from clóse packing may be seen. Very simple hydrogen bonded compounds can have very complex crýstal structures, for instance, ice, hydroquinone and trimesic acid. The prediction of crystal packings of such compounds may therefore be quite unreliable.

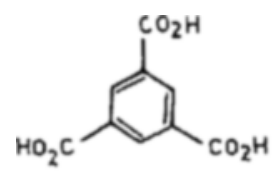<smiles>Oc1ccc(O)cc1</smiles>

Chart 3.

The situation appears to be more tractable when very weak directional interactions are considered. A typical example is the $\mathrm{Cl} \ldots \mathrm{Cl}$ interaction which is manifested as short $(3.2$ to $3.6 \mathrm{~A})$ intermolecular contacts in the crystal structures of polychloro compounds. A recent paper (Williams and Hsu 1985) estimates the stabilization energy of such an interaction to be about $3 \%$ of a covalent $\mathrm{Cl}-\mathrm{Cl}$ bond. Since these weak 'bonds' are directional, they result in deviations from Kitaigorodskii close-packing, but since they are much weaker than, say $\mathrm{O}-\mathrm{H} \ldots \mathrm{O}$ hydrogen bonding, gross variations are ustally not encountered. However, it seems that $\mathrm{Cl} \ldots \mathrm{Cl}$ interactions are sufficientty important to cause violations in the $\mathrm{Cl}-\mathrm{Me}$ exchange rule.

Interactions of the $\mathrm{Cl} \ldots \mathrm{Cl}$ type are particularly common in the $4 \mathrm{~A}$-short axis structures ( $\beta$-structures) of planar chloro-aromatic compounds. Many simple polychlorobenzenes such as the ones shown below adopt this structure which is characterised by a highly overlapped stacking stabilised by $\mathrm{C} \ldots \mathrm{C}$ interactions (chart 4). Hexachlorobenzene (HCLBNz) exemplifies this structural type. Figure 3 which is a stereoview of the crystal structure of HCLBNZ shows that $\mathrm{Cl} \ldots \mathrm{Cl}$ contacts of $3.72 \mathrm{~A}$<smiles>Clc1ccc(Cl)cc1</smiles><smiles>Clc1cc(Cl)cc(Cl)c1</smiles><smiles>Clc1cc(Cl)c(Cl)cc1Cl</smiles><smiles>Clc1cc(Cl)c(Cl)c(Cl)c1Cl</smiles><smiles>Clc1c(Cl)c(Cl)c(Cl)c(Cl)c1Cl</smiles>

HCLBNZ

Chart 4. 
result in the molecules being arranged along linear ribbons which are then stacked at the short axis separation. Successive stacks are related by two-fold screw axes and are held together by additional $\mathrm{Cl} \ldots \mathrm{Cl}$ contacts of $3.51 \mathrm{~A} . \mathrm{Cl} \ldots \mathrm{Cl}$ interactions therefore play a crucial role in stabilizing this structure (Sarma and Desiraju 1985).

Hence, it should be no surprise that the crystal structures of HCLBNZ and hexamethylbenzene (HMBENz) are quite different and that the Cl-Me exchange is not valid here. In the latter structure, molecules are arranged in planar pseudo-hexagonal sheets which are stacked at 3.66 A separation. The distance between methyl groups on adjacent molecules in a sheet is $3.90 \mathrm{~A}$, which means that normal ciose-packing is observed here (figure 4). These structural anomalies are not peculiar to the HCLBNzHMBENz pair. In fact the Cl-Me exchange is rarely if ever applicable if all the $\mathrm{Cl}$ groups are replaced by $\mathrm{Me}$ groups in planar polychloro compounds. The significance of the failure of complete $\mathrm{Cl}$-Me exchange in HCLaNz is that it demonstrates that $\mathrm{Cl} \ldots \mathrm{Cl}$ interactions are attractive. in nature and directional in character. In other words, chloro groups may often function as having specific, anisotropic, electronic effects rather than just as groups of a certain volume.

Another very suggestive manifestation of these effects is shown by the pair of compounds $2,2^{\prime}$-dichloro- and 2,2'-dimethylbenzidine. The crystal structures of these two compounds are quite different as are the molecular conformations in the solid state. While the angle between the two rings in the dimethyl compound is $86^{\circ}$, the corresponding angle for the dichloro derivative is only $36^{\circ}$ with a very short nonbonded distance between the two intramolecular $\mathrm{Cl}$ atoms. This is an unambiguous violation of the $\mathrm{Cl}-\mathrm{Me}$ rule.
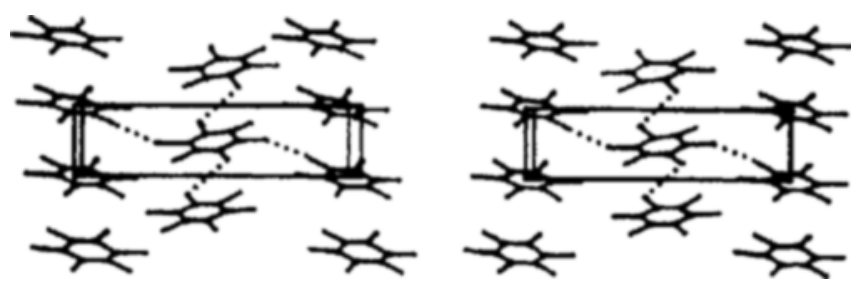

Figure 3. Stereoview of the crystal structure of hexachlorobenzene (HCLBNZ). Notice the linear ribbons interconnected by $\mathrm{Cl} \ldots \mathrm{Cl}$ contacts.

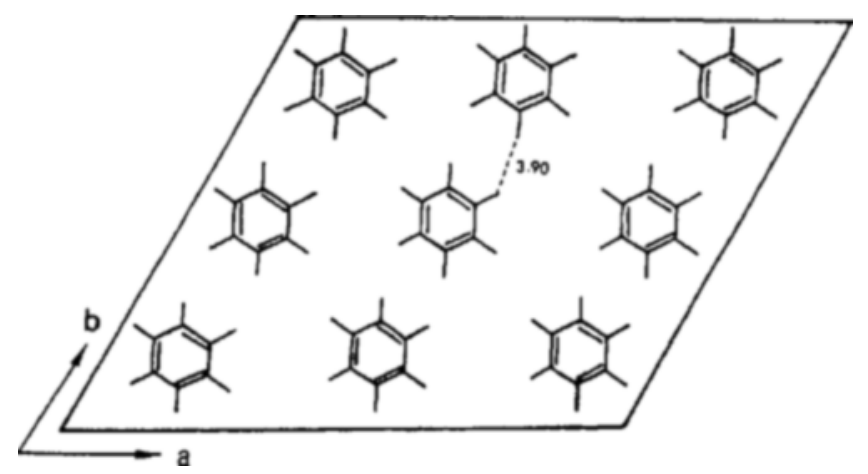

Figure 4. Projection of the crystal structure of hexamethylbenzene (HMBENZ), down the $c$ axis to the planar sheet. 

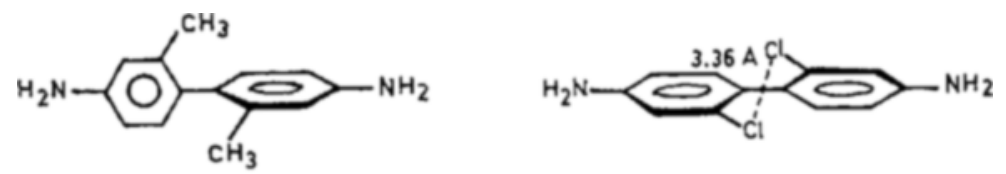

Chart 5.<smiles>Clc1c(Cl)c(Cl)c(Cl)c(Cl)c1Cl</smiles><smiles>Cc1c(Cl)c(Cl)c(Cl)c(Cl)c1Cl</smiles><smiles>Cc1c(C)c(Cl)c(Cl)c(Cl)c1Cl</smiles><smiles>Cc1c(Cl)c(C)c(Cl)c(C)c1Cl</smiles>

laomorphous with HCL.BNZ Monoelinie $\mathrm{P}_{2}, \mathrm{e}$<smiles>Cc1c(Cl)c(Cl)c(C)c(Cl)c1Cl</smiles>

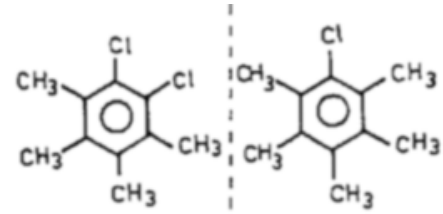<smiles>Cc1c(C)c(Cl)c(Cl)c(C)c1Cl</smiles>
ct<smiles>Cc1c(C)c(C)c(Cc2c(C)c(C)c(Cl)c(C)c2CI(I)I(C)I)c(C)c1C</smiles>
HMBEN2 lamorphnus with HMAENZ Iriclinie pì pseudoheraqnanal

Chart 6.

Interestingly, $\mathrm{Cl}-\mathrm{Me}$ exchange in HCLBNZ is valid to a limited extent in that it is possible to substitute some of the $\mathrm{Cl}$ groups by Me groups without altering the crystal structure. Thus if upto any three $\mathrm{Cl}$ atoms in HCLBNZ are replaced by $\mathrm{Me}$, a disordered isomorphous structure results. While 1,2- and 1,4-dichlorotetramethylbenzenes also have the same disordered $4 \AA$ structure, chloropentamethylbenzene is disordered but isomorphous with HMBENz. These structures represent cases where the attractive $\mathrm{Cl}$... $\mathrm{Cl}$ forces from the unexchanged $\mathrm{Cl}$ groups are countered by $\mathrm{H}$. . H repulsions which result on crowding the Me groups into those positions previously occupied by $\mathrm{Cl}$, with the change in structural type occurring between one and two $\mathrm{Cl}$ groups. Partial $\mathrm{Cl}-\mathrm{Me}$ exchange is permitted in these cases since some $\mathrm{Cl} \ldots \mathrm{Cl}$ interactions are still possible.

\section{Conclusions}

(a) The Cl-Me exchange rule follows from the Kitaigorodskii close-packing model for organic molecular crystals and is valid for, typically, large, irregularly shaped molecules or those with a small number of $\mathrm{Cl}$ atoms (say, one).

(b) When the number of $\mathrm{Cl}$ atoms per molecule is more than one and/or when the molecule becomes more planar and regular in shape, $\mathrm{Cl}-\mathrm{Me}$ exchange need not apply. (c) In these latter cases, the crystal structures are characterised by short $\mathrm{Cl} \ldots \mathrm{Cl}$ contacts and the anomalies in the Cl-Me exchange show up the limitations inherent in a purely geometrical approach and must be regarded as indicators for specific $\mathrm{Cl} \ldots \mathrm{Cl}$ interactions which cannot be incorporated into the geometrical model. 


\section{Acknowledgments}

We thank the DST (SERC) and the UGC, New Delhi, for financial assistance.

\section{References}

Desiraju G R 1984 Endeavour 8201

Jones W, Ramdas S, Theocharis C R, Thomas J M and Thomas N W 1981 J. Phys. Chem. 852594

Jones W, Theocharis C R, Thomas J M and Desiraju G R $1983 \mathrm{~J}$. Chem. Soc., Chem. Commum. 1443

Kitaigorodskii A I 1973 'Molecular crystals ond molecules' (New York: Academic Press)

Sarma J A R P and Desiraju G R 1985 Chem. Phys. Lett. 117160

Simonetta M 1974 Acc. Chem. Res. 7345

Theocharis C R, Desiraju G R and Jones W 1984 J. Am. Chem. Soc. 1063606

Thomas J M 1974 Philos. Trans. R. Soc. London A277 251

Williams D E and Hsu L-Y 1985 Acta Cryst. A41 296 